\title{
Agôn
}

Revue des arts de la scène

Critiques | Saison 2012-2013

\section{Mon Amour, de Thomas Ferrand}

L'amour et son motif

\section{Caroline Châtelet}

\section{Q OpenEdition}

Journals

Édition électronique

URL : http://journals.openedition.org/agon/2603

DOI : 10.4000/agon.2603

ISSN : 1961-8581

Éditeur

Association Agôn

Référence électronique

Caroline Châtelet, " Mon Amour, de Thomas Ferrand », Agôn [En ligne], Critiques, mis en ligne le 31 mai 2013, consulté le 23 septembre 2020. URL : http://journals.openedition.org/agon/2603 ; DOI : https:// doi.org/10.4000/agon.2603

Ce document a été généré automatiquement le 23 septembre 2020

Association Agôn et les auteurs des articles 


\title{
Mon Amour, de Thomas Ferrand
}

\author{
L'amour et son motif
}

\author{
Caroline Châtelet
}

\section{RÉFÉRENCE}

Mon Amour, de Thomas Ferrand - Théâtre de la Cité Internationale, Paris - du 13 mai au 1er juin 2013

http://www.theatredelacite.com

1 Dans l'un de ses précédents spectacles, Extase de Sainte Machine, Thomas Ferrand mettait en scène deux comédiens dans un espace nu. Debout avec à leurs pieds un pack de bières, ceux-ci ne bougeaient pas, ne parlaient pas, seule l'intensité lumineuse et la musique amenant le mouvement. Proposition radicale par son atmosphère dérivant du contemplatif à l'hypnotisme, Extase de Sainte-Machine frôlait, aussi, une forme d'hermétisme. Comme si à vouloir travailler sur des états statiques, sur le motif - motif des corps face aux couleurs et aux sons - Thomas Ferrand s'enferrait dans une forme sans pouvoir la renouveler ni l'interroger. C'est ce tropisme du motif, plutôt intéressant par sa volonté d'explorer un état et d'en définir les contours et limites, que l'on retrouve dans Mon Amour. Là, le metteur en scène prend comme matériau initial la figure de Dom Juan. Il ne s'agit pas ici de donner à entendre la pièce de Molière, mais une partie du dialogue entre Dom Juan et Charlotte, soit la déclaration et les serments du jeune homme à la paysanne. Ce texte, c'est Laurent Frattale, comédien avec qui Thomas Ferrand collabore régulièrement, qui l'apporte. C'est le même Frattale que l'on retrouve en scène, avec face à lui Sandra Devaux en mutine et insolente Marguerite (en alternance avec Virginie Vaillant). Tous deux, dans un jeu parfaitement maîtrisé et un mouvement allant crescendo, se livrent à la répétition inlassable du dialogue. Dans ce qui devient autant une jolie joute verbale et physique qu'un exercice ludique et déraisonné, les comédiens portent le texte jusqu'à le vriller. Le rythme s'accélère, les gestes deviennent absurdes et la conversation elle-même s'enraye, les rôles s'inversent, se reprennent ou se répètent. L'atmosphère sucrée de beauté et de pureté initiale renvoyant à la sincérité (?) de la déclaration d'amour cède la place à la colère et au 
dérèglement, avant de se suspendre brusquement. Sans résolution ni achèvement - on vous l'a dit, la question ici est celle du motif et de sa déstructuration - mais sans, non plus, réaliser la mise à nu annoncée [" Mon Amour est une version hallucinée du Dom Juan de Molière dont il ne subsiste qu'une logorrhée infernale et saccagée", Thomas Ferrand, extrait du dossier de presse du spectacle]. Et tandis que la destruction du dialogue et du jeu, en se donnant comme trop lisible, volontariste et appuyée, empêche l'installation d'une véritable tension, le "saccage " lui-même laisse un goût d'inachevé. Le démontage de la mécanique amoureuse demeurant seulement esquissé, Mon Amour s'offre comme un geste à la beauté formelle réelle - telle la scénographie fleurie aux teintes pastels de Sallahdyn Khatir à l'esthétique séduisante - et au propos embryonnaire et léger.

\section{Mon Amour de Thomas Ferrand}

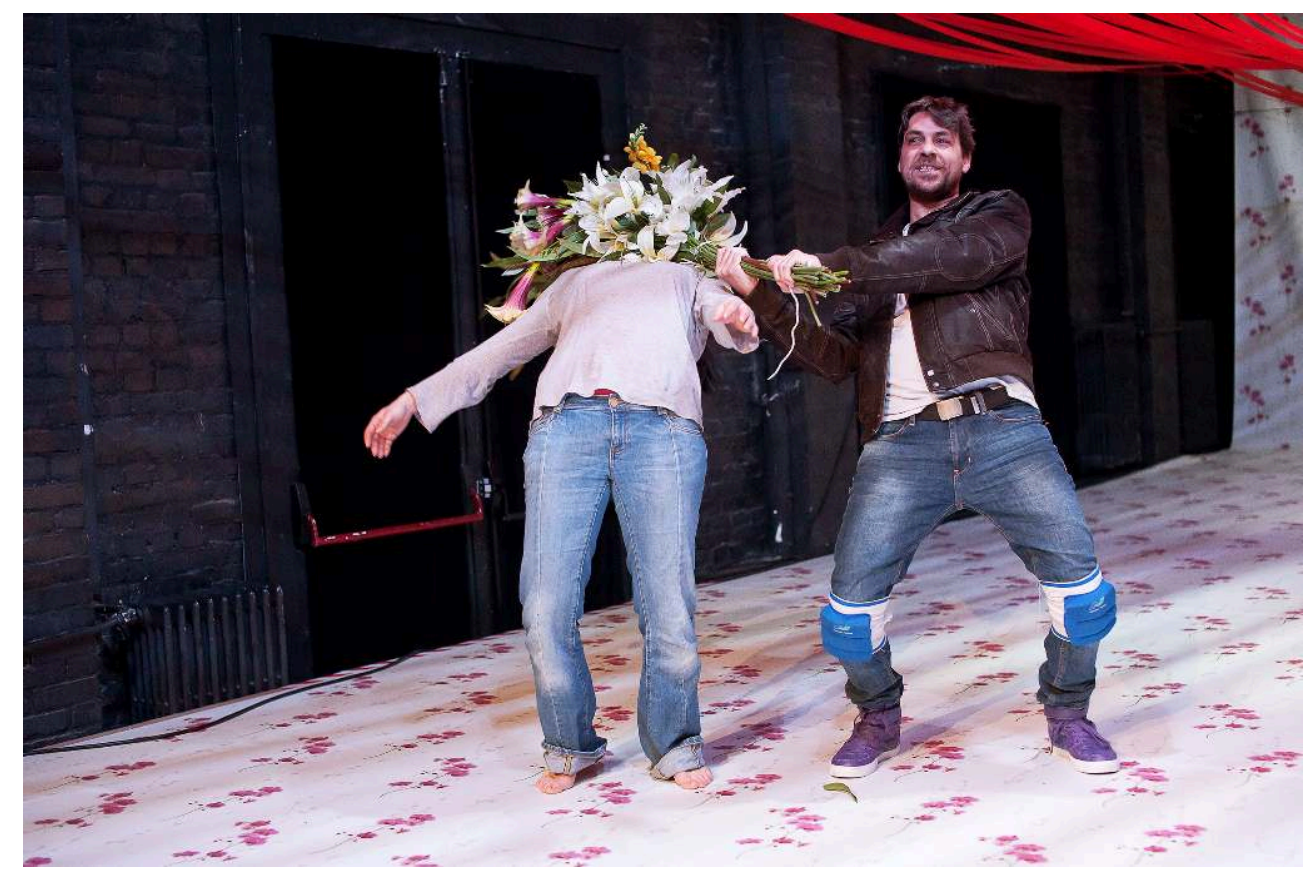

(c) Mathilde Delahaye 